ISSN 0103-8478

\title{
Retenção de placenta no proteinograma de vacas Holandesas
}

\author{
Retained placenta on the proteinogram of Holstein cows
}

\author{
João Paulo Elsen Saut ${ }^{\mathrm{I}}$ Samantha Ive Miyashiro ${ }^{\mathrm{II}}$ \\ Raquel Fraga e Silva Raimondo ${ }^{\text {II }}$ Mariana Tikuma Nunes ${ }^{\text {II }}$ Clara Satsuki MoriI \\ Jose Jurandir Fagliari ${ }^{I I I}$ Eduardo Harry Birgel Junior ${ }^{\text {IV }}$
}

RESUMO

Com o objetivo de avaliar a influência da retenção de placenta (RP) no proteinograma de fêmeas bovinas da raça Holandesa, de propriedades comerciais, foram utilizadas 129 vacas com RP e 145 vacas com parto e pós-parto fisiológicos e sem nenhum tratamento no período avaliado. As amostras de sangue

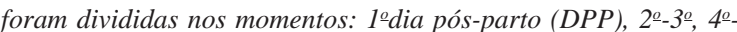
$5^{\circ}, 6^{\circ}-7^{\circ}, 8^{\circ}-14^{\circ}, 15^{\circ}-29^{\circ}, 30^{\circ}-59^{\circ}$ e $60^{\circ}-90^{\circ} \mathrm{DPP}$. O fracionamento das proteínas foi realizado por eletroforese em fita de acetato de celulose e em gel de poliacrilamida, contendo dodecil sulfato de sódio (SDS-PAGE), nas quais se avaliou o comportamento de 19 bandas proteicas identificadas pelos respectivos pesos moleculares, que variaram entre $23 \mathrm{KDa}$ e $187 \mathrm{KDa}$. Não houve influência da RP na proteína sérica total e gamaglobulinas. A albumina sérica permaneceu abaixo dos valores de referência até os 90DPP nos animais com RP. Concluiu-se que vacas Holandesas com RP apresentam um quadro de normoproteinemia com hipoalbuminemia e aumento das frações alfaglobulinas $e$ betaglobulinas até os $90 D P P$, presença de resposta inflamatória de fase aguda positiva pelo significativo aumento de haptoglobina, ceruloplasmina, glicoproteína ácida, e de fase aguda negativa pela diminuição de albumina na primeira semana pós-parto.

Palavras-chave: bovinos, puerpério, proteínas de fase aguda, SDS-PAGE.

\section{ABSTRACT}

The aim of this study was to evaluate the influence of retained placenta on the proteinogram of Holstein cows from commercial dairy farms. Blood samples were collected from 129 animals with retained placenta (RP) and 145 animals with normal delivery and postpartum period, without any treatment, on following days: $1^{\text {st }}$ day in milk (DIM), $2^{\text {nd }}-3^{\text {th }}, 4^{\text {th }}-5^{\text {th }}, 6^{\text {th }}-7^{\text {th }}, 8^{\text {th }}-$ $14^{\text {th }}, 15^{\text {th }}-29^{\text {th }}, 30^{\text {th }}-59^{\text {th }}$ and $60^{\text {th }}-90^{\text {th }}$ DIM were analyzed. Protein electrophoresis were performed in acetate cellulose and sodium dodecyl sulfate polyacrilamide gel (SDS-PAGE), where 19 protein bands were observed with molecular weights between 23KDa and $187 \mathrm{KDa}$. There was no influence on serum total protein and gamma globulins. Serum albumin remained below the normal reference values up to 90DIM. In conclusion, Holstein cows with RP have normoproteinemia with hypoalbuminemia up to 90DIM, presence of positive acute phase response by increase of haptoglobin, ceruloplasmin, acid glycoprotein, alpha and beta globulins and negative acute phase response by decreased of albumin within the first week postpartum.

Key words: bovine, puerperium, acute phase proteins, SDS-PAGE.

\section{INTRODUÇÃO}

Problema reprodutivo é a principal causa de descarte involuntário nas propriedades leiteiras e não está associado com o descarte do animal por alterações na produção leiteira (BONNEVILLEHÉBERT et al., 2011). Dentre as doenças reprodutivas mais comuns, destaca-se a retenção de placenta (RP), com incidências observadas de 4,3\% em 418.383 partos no Canadá (BONNEVILLE-HÉBERT et al., 2011), 5,2\% em 57.301 partos no Irã (HOSSEINZADEH \& ARDALAN, 2011) e no Brasil, em Minas

\footnotetext{
IFaculdade de Medicina Veterinária (FAMEV), Universidade Federal de Uberlândia (UFU), Av. Pará, 1720, Bloco 2T, Umuarama, 38400-902, Uberlândia, MG, Brasil. E-mail: jpsaut@famev.ufu.br. Autor para correspondência.

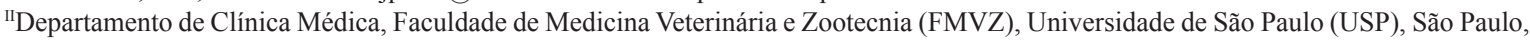
SP, Brasil.

IIIDepartamento de Clínica e Cirurgia Veterinária, Faculdade de Ciências Agrárias e Veterinárias de Jaboticabal (FCAV), Universidade Estadual Paulista Júlio de Mesquita Filho (UNESP), Jaboticabal, SP, Brasil.

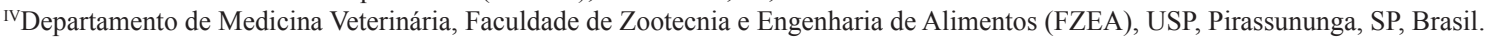
Recebido 30.05.13 Aprovado 27.12.13 Devolvido pelo autor 20.06.14 CR-2013-0762.R1
} 
Gerais, incidência de 10,54\% em 1.875 parições (FERNANDES et al., 2001).

A RP é responsável por grande perda econômica por causar baixo desempenho reprodutivo, alta incidência de infecções uterinas até os 30 dias pós-parto (DPP) e aumentar o risco de ocorrências de metrite (HOSSEIN-ZADEH \& ARDALAN, 2011). Verifica-se também que vacas com RP têm níveis significativamente mais baixos de imunoglobulinas no colostro (LONA \& ROMERO, 2001) e aumentam a ocorrência de distúrbios metabólicos como a Cetose (CURTIS et al., 1985).

O diagnóstico exato e precoce de doenças no periparto de vacas leiteiras por meio do exame clínico, técnicas diagnósticas eficazes e interpretação correta de exames laboratoriais é fator imprescindível para manutenção da produtividade animal. O proteinograma é uma das ferramentas que pode auxiliar no monitoramento de enfermidades infecciosas, sendo o fracionamento eletroforético das proteínas sanguíneas um dos métodos mais confiáveis para a sua identificação (FAGLIARI \& SILVA, 2002).

Como alternativa para aumentar o número de proteínas identificadas e auxiliar no diagnóstico, recomenda-se a utilização da técnica de eletroforese em gel de poliacrilamida, contendo dodecil sulfato de sódio (SDS-PAGE). A SDS-PAGE possibilita a visualização de concentrações proteicas extremamente baixas e a identificação de 20 a 30 proteínas com pesos moleculares entre 24 a $340 \mathrm{KDa}$ (FAGLIARI \& SILVA, 2002). Por meio dessa técnica, é possível a quantificação de proteínas de fase aguda (PFA), permitindo o reconhecimento precoce de processos inflamatórios (HORADAGODA et al., 1999).

Objetivou-se neste experimento caracterizar o proteinograma de vacas Holandesas com retenção de placenta, através das técnicas de eletroforese em fitas de acetato de celulose e eletroforese em gel de poliacrilamida, contendo dodecil sulfato de sódio (SDS-PAGE).

\section{MATERIAL E MÉTODOS}

Foram utilizadas 374 vacas da raça Holandesa, provenientes de três propriedades leiteiras de Pirassununga - São Paulo, criadas em sistema intensivo de produção do tipo Freestall, com manejos sanitários e reprodutivos semelhantes e assistidas por médicos veterinários. A existência de fichas individuais dos animais possibilitou a associação do exame clínico à análise do histórico, permitindo a seleção dos animais e a formação de grupos homogêneos para avaliação da influência da retenção de placenta no proteinograma.
As amostras foram colhidas em oito

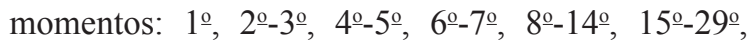
$30^{\circ}-59^{\circ}$ e $60^{\circ}-90^{\circ}$ DPP, e os animais divididos em dois grupos: a) Grupo Fisiológico (Gr.F), 145 vacas com parto e pós-parto fisiológicos que não apresentaram nenhum sinal clínico de doença e não tiveram nenhum tratamento com antibióticos e/ou hormônios no período avaliado; b) Grupo Retenção de Placenta (Gr.RP): 129 vacas que retiveram placenta e foram tratadas 12 horas pós-parto com uma única aplicação de $20 \mathrm{mg} \mathrm{kg}^{-1}$ de oxitetraciclina $20 \%$ intra-muscular. Três vacas foram tratadas com infusão intra-uterina de $20 \mathrm{ml}$ de oxitetraciclina $20 \%$ e tratamento suporte, após o tratamento parenteral, por apresentarem metrite, e foram descartadas do experimento. Também foram eliminados do presente experimento todos os animais em que houve o diagnóstico de doenças intercorrentes e tiveram que ser tratados em ambos os grupos. Adotou-se este critério por serem propriedades leiteiras particulares e para padronizar o tratamento único a base de oxitetraciclina em apenas um momento no pós-parto.

Apenas vacas negativas aos exames periódicos de brucelose e tuberculosee não reagentes ao antígeno do vírus da leucose bovina foram utilizadas. O diagnóstico da leucose foi efetuado pela técnica de imunodifusão radial dupla de Ouchterlony (BIRGEL, 1982). As amostras de sangue foram coletadas por punção da veia jugular, utilizando-se o sistema vacutainer sem anticoagulante, centrifugadas e o soro congelado a menos $20^{\circ} \mathrm{C}$. Para o fracionamento das proteínas séricas, foram realizadas duas técnicas de eletroforese. Na técnica de eletroforese em fita de acetato de celulose, a migração eletroforética foi realizada em fitas de acetato de celulose e a leitura das frações albumina, alfaglobulina, betaglobulina e gamaglobulina efetuadas por densitometria (SOUZA et al., 2010).

A eletroforese em gel de poliacrilamida contendo dodecil sulfato de sódio (SDS-PAGE) foi realizada, de acordo com FAGLIARI \& SILVA (2002), em uma unidade de eletroforese vertical (modelo EV5-2001N, marca Bioagency ${ }^{\circledR}$ ). As leituras das frações foram realizadas no densitômetro (escâner Epson Expression 1680, marca Byosistems ${ }^{\circledR}$ ) e software de análise de imagens (VisionWorks LS, Ultra-VioletProducts ${ }^{\circledR}$ ). Para perfeita identificação das frações proteicas do soro, utilizou-se um marcador padrão de pesos moleculares (Invitrogen ${ }^{\circledR}$ ), com bandas entre 10 e $220 \mathrm{kDa}$. As proteínas albumina, alfaglobulinas, betaglobulinas e gamaglobulinas foram mensuradas através da eletroforese em fita de acetato de celulose, enquanto as proteínas ceruloplasmina, hemopexina, 
haptoglobina, glicoproteína ácida foram identificadas por seus pesos moleculares, conhecidos (FAGLIARI \& SILVA, 2002) através da eletroforese SDS-PAGE.

A análise estatística foi realizada no programa estatístico Minitab 15 (Minitab Inc ${ }^{\circledR}$, Pennsylvania, USA). Para avaliar a influência da RP no proteinograma, os dois grupos foram comparados nos DPP, sendo, inicialmente, realizado o Teste de Kolmogorov-Smirnov para verificar se os dados apresentavam ou não distribuição normal. As variáveis com distribuição normal foram submetidas ao teste de comparação de médias pelo teste TStudent. As variáveis com distribuição não-paramétrica foram analisadas pelo teste de Mann-Whitney. Todos os testes apresentaram níveis de significância igual a 5\% $(\mathrm{P}=0,05)$.

\section{RESULTADOS E DISCUSSÃO}

O presente trabalho verificou que a RP interfere de maneira significativa no proteinograma de vacas leiteiras criadas em sistema intensivo do tipo Freestall no Estado de São Paulo. Em ambas as técnicas utilizadas, foram demonstradas estas alterações, sendo que, com o uso da SDS-PAGE, permitiu-se a identificação de proteínas de fase aguda, as quais serão mais abordadas por sua importância clínica. Além destas PFA, foram identificadas outras proteínas apenas pelo peso molecular e que a literatura consultada ainda não apresenta dados para serem discutidos e comparados, no entanto, considera-se de grande importância científica a apresentação desses resultados, pois não existe esta informação na literatura.

Em relação ao perfil sérico proteico (Figura 1), os teores de proteínas totais (PT) apresentaram diferença apenas aos 15-29DPP. Os

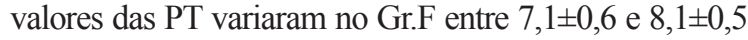
$\mathrm{gdL}^{-1}$ e no Gr.RP entre $7,0 \pm 0,7 \mathrm{e} 7,6 \pm 0,9 \mathrm{gdL}^{-1}$. No entanto, os dois grupos permaneceram dentro dos valores de referência para vacas Holandesas (SOUZA et al., 2008), criadas no estado de São Paulo, no puerpério recente $\left(7,6 \pm 0,7 \mathrm{gdL}^{-1}\right)$ e na fase pós-puerperal $\left(8,8 \pm 0,7 \mathrm{gdL}^{-1}\right)$. GONÇALVES \& KOZICKI (1997) observaram um gasto excessivo de proteínas até o quinto DPP, em vacas com RP, e MULEI et al. (1993) apresentaram resultados semelhantes ao da presente pesquisa.

As concentrações de albumina, avaliadas através da eletroforese em fita de acetato de celulose, foram menores no Gr.RP desde o 2 -DPP e oscilaram entre 2,3 $\pm 0,4$ e 2,9 $\pm 0,3 \mathrm{gdL}^{-1}$ (Figura 1). O Gr.RP manteve-se abaixo dos valores fisiológicos de vacas Holandesas no puerpério recente $\left(2,9 \pm 0,3 \mathrm{gdL}^{-1}\right)$ e pós-puerperal $(3,2 \pm 0,2$ $\mathrm{gdL}^{-1}$ ) (SOUZA et al., 2008) e apresentaram o mesmo comportamento descrito por SOUZA et al. (2010), em vacas Holandesas com $\mathrm{RP}\left(2,7 \pm 0,4 \mathrm{gdL}^{-1}\right)$. GONÇALVES

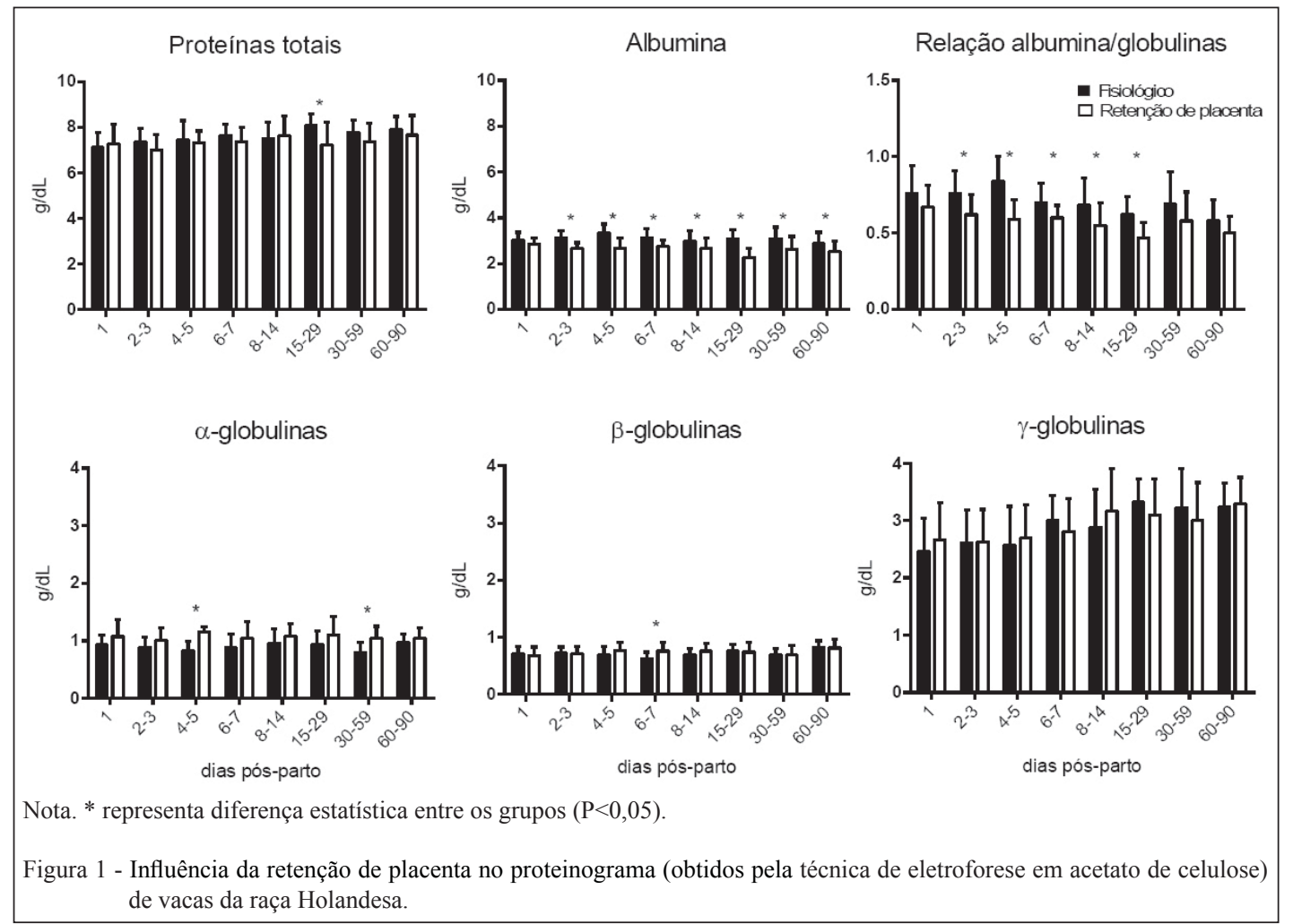

Ciência Rural, v.44, n.9, set, 2014. 
\& KOZICKI (1997) verificaram a diminuição de albumina em ambos os grupos.

A eletroforese em gel de poliacrilamida contendo dodecil sulfato de sódio (SDS-PAGE) a 10\%, como utilizado na presente pesquisa, não permitiu a perfeita separação da fração albumina. As frações proteicas identificadas como transferrina (78KDa), albumina $(62 \mathrm{KDa})$ e imunoglobulinas de cadeia pesada $(53 \mathrm{KDa})$ apresentaram sobreposição na SDSPAGE, o que dificultou a marcação com precisão de início e fim de cada fração e sendo a possível causa de um aumento nas concentrações de albumina.

Os valores médios encontrados para a albumina no SDS-PAGE foram maiores do que os encontrados na fita de acetato de celulose em todos os momentos estudados. Verificou-se que a eletroforese em fita de acetato, técnica mais acessível e de maior facilidade operacional (KANEKO et al., 2008), permitiu que a identificação e quantificação da fração albumina fosse mais fidedigna do que na SDS-PAGE e, por este motivo, os resultados apresentados foram apenas da eletroforese em fita de acetato de celulose.

Apesar de vacas com RP terem maior risco de distúrbios metabólicos como a Cetose (CURTIS et al., 1985) e, de acordo com CHAPINAL et al. (2011), a RP e metrite estarem relacionadas com balanço energético negativo e redução de até $30 \%$ na ingestão de matéria seca no periparto, a possibilidade de relacionar-se hipoalbuminemia observada na presente pesquisa com distúrbios do metabolismo energético foi descartada, pois a mobilização de gordura no periparto e consequente esteatose hepática associada a lesões hepáticas agudas é pequena. SOUZA et al. (2010), em vacas da raça Holandesa, criadas no Vale do Paraíba/SP, com produção leiteira média entre 15 e 25 litros de leite por dia, não demonstraram existir alterações nos teores séricos de colesterol, ácidos graxos não esterificados e $\beta$-hidroxibutirato em decorrkncia de distúrbios do puerpério recente (endometrite puerperal aguda e a retenção de placenta) e do puerpério tardio (catarros genitais). Da mesma forma, a suposição de que a absorção de endotoxinas, em vacas com infecções uterinas, poderia determinar lesões hepáticas também foi descartada por SOUZA et al. (2010), pois esses autores não evidenciaram qualquer alteração nos valores das enzimas hepáticas AST, GGT e teores séricos de bilirrubinas.

Dessa forma, a diminuição nos teores séricos de albumina deve ser entendida como resposta frente ao processo inflamatório induzido pela RP, pois a albumina é considerada PFA negativa (KANEKO et al., 2008). A RP é considerada fator de risco para a instalação de infecções uterinas, visto que atrasa a involução uterina e eliminação do lóquio, provoca lesões teciduais e inibe determinadas funções dos neutrófilos (LEBLANC et al., 2002). Sugere-se que os eventos acima relacionados devam coexistir, interferindo de forma variada e individual, resultando em menor aporte de albumina na circulação sanguínea e, desta forma, prejudicando suas funções biológicas de manutenção da pressão oncótica do fluido intravascular e nos processos de transportes de substâncias (JAIN, 1989).

As alfaglobulinas apresentaram-se aumentadas aos 4-5 DPP e as betaglobulinas aos 6-7 DPP no Gr.RP, confirmando a resposta inflamatória de fase aguda estimulada pela RP, pois nestas frações estão distribuídas as PFAs positivas (KANEKO et al., 2008). As gamaglobulinas não sofreram influência da RP (Figura 1). Na literatura consultada, não foram encontrados trabalhos com hemopexina (87KDa) que pudessem ser confrontados com os resultados encontrados. As PFAs ceruloplasmina, haptoglobina (Hp) e glicoproteína ácida permaneceram aumentadas no Gr.RP até os 15 DPP, com aumento significativo mais precoce na glicoproteína ácida (2-3 DPP) de $83,4 \pm 39,0 \mathrm{gdL}^{-1}$ (Gr.RP) e 50,4 $\pm 46,8 \mathrm{gdL}^{-1}$ (Gr.F).

$\mathrm{Na} \mathrm{Hp}$ e ceruloplasmina, houve diferença entre os grupos aos 6-7DPP, com a queda da concentração destas proteínas no Gr.F. O Gr.RP apresentou Hp, no $6^{\circ}$ e 7 o DPP, igual a $167,2 \pm 114,9$ $\mathrm{gdL}^{-1}$ contra $29,1 \pm 24,6 \mathrm{gdL}^{-1}$ do Gr.F, quase seis vezes maior; o mesmo ocorreu com a glicoproteína ácida, de $85,7 \pm 86 \mathrm{gdL}^{-1}$ contra $13,5 \pm 13,4 \mathrm{gdL}^{-1}$, respectivamente, nos Gr.RP e Gr.F (Figura 2).

Segundo SKINNER et al. (1991), o trauma da parição não influencia na concentração de $\mathrm{Hp}$ e sim a infecção uterina pós-parto, pois verificaram aumento significativo de $\mathrm{Hp}$ apenas em animais com RP entre 3 e 5 DPP. Concluíram que a Hp poderia avaliar a integridade uterina no pós-parto. WILLIAMS et al. (2007) associaram o aumento de Hp com a contaminação bacteriana no lumen uterino. HIRVONEN et al. (1999) somente encontraram o aumento de HP nos casos de metrite aguda severa e com mau prognóstico à performance reprodutiva. Finalmente, HUZZEY et al. (2009) não associaram a presença de RP com aumento de Hp, mas sim como fator predisponente de infecção uterina.

Com base na literatura, sugere-se que o aumento verificado nas PFAs é devido ao estímulo provocado pela infecção bacteriana associada à RP, pois animais com RP apresentam seis vezes mais chance de desenvolverem infecções uterinas (LEBLANC et al., 2002). O Gr.RP foi imediatamente tratado para evitar a presença de 


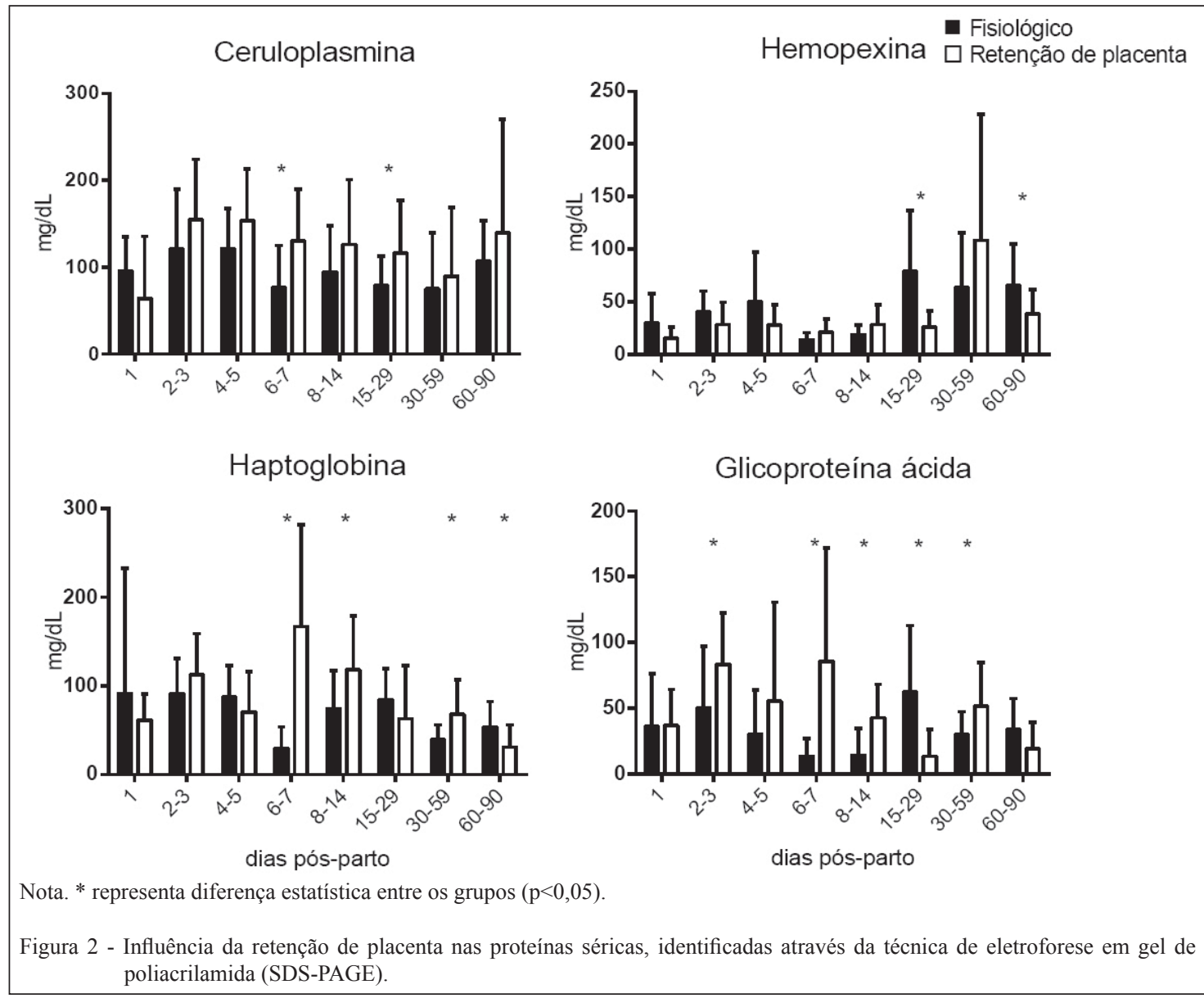

enfermidades uterinas concomitantes durante $\mathrm{o}$ experimento. Apesar do tratamento instituído, esses animais apresentaram picos das PFAs semelhante a animais com infecções uterinas (HIRVONEN et al.,1999; HUZZEY et al., 2009; CHAN et al., 2010).

Outro fator a ser considerado no pós-parto é que a Hp pode ser indicadora de lipidose hepática, pois, semelhante a infecções e traumas, a deposição lipídica hepática estimula hepatócitos na produção de Hp (KATOH, 2002). Como já discutido, vacas com RP têm maior chance de distúrbios metabólicos nesta fase e consequente deposição lipídica.

$\mathrm{Na}$ figura 3, estão apresentadas as proteínas que não puderam ser identificadas e estão apresentadas apenas com o peso molecular. De acordo com PASSOS (2004), além das PFAs, a identificação de outras proteínas séricas tornou-se útil como indicador do estado de sanidade e/ou imunológico (PASSOS, 2004). Na literatura consultada, não foram encontradas pesquisas que avaliaram o comportamento destas proteínas no puerpério e em animais com RP, sendo, portanto, o primeiro trabalho que se preocupou em apresentar estas informações.
Ressalta-se a carência e necessidade de mais pesquisas focadas nessas proteínas, no intuito de avaliar seus efeitos e importância biológica em vacas leiteiras.

\section{CONCLUSÃO}

A retenção de placenta influencia significativamente no proteinograma de vacas Holandesas, caracterizado por normoproteinemia com hipoalbuminemia até os 90 dias pós-parto; presença de resposta inflamatória de fase aguda positiva pelo significativo aumento de haptoglobina, ceruloplasmina, glicoproteína ácida, alfaglobulinas e betaglobulinas e de fase aguda negativa pela diminuição de albumina na primeira semana pós-parto.

\section{AGRADECIMENTOS}

Ao Conselho Nacional de Desenvolvimento Científico e Tecnológico (CNPq), pela concessão de bolsa de doutorado realizado no curso de pós-graduação em Clínica Veterinária da Faculdade de Medicina Veterinária e Zootecnia (FMVZ)- Universidade de São Paulo (USP), e à Fundação de Amparo à Pesquisa do Estado de São Paul (FAPESP), pelo apoio financeiro de auxílio à pesquisa.

Ciência Rural, v.44, n.9, set, 2014. 


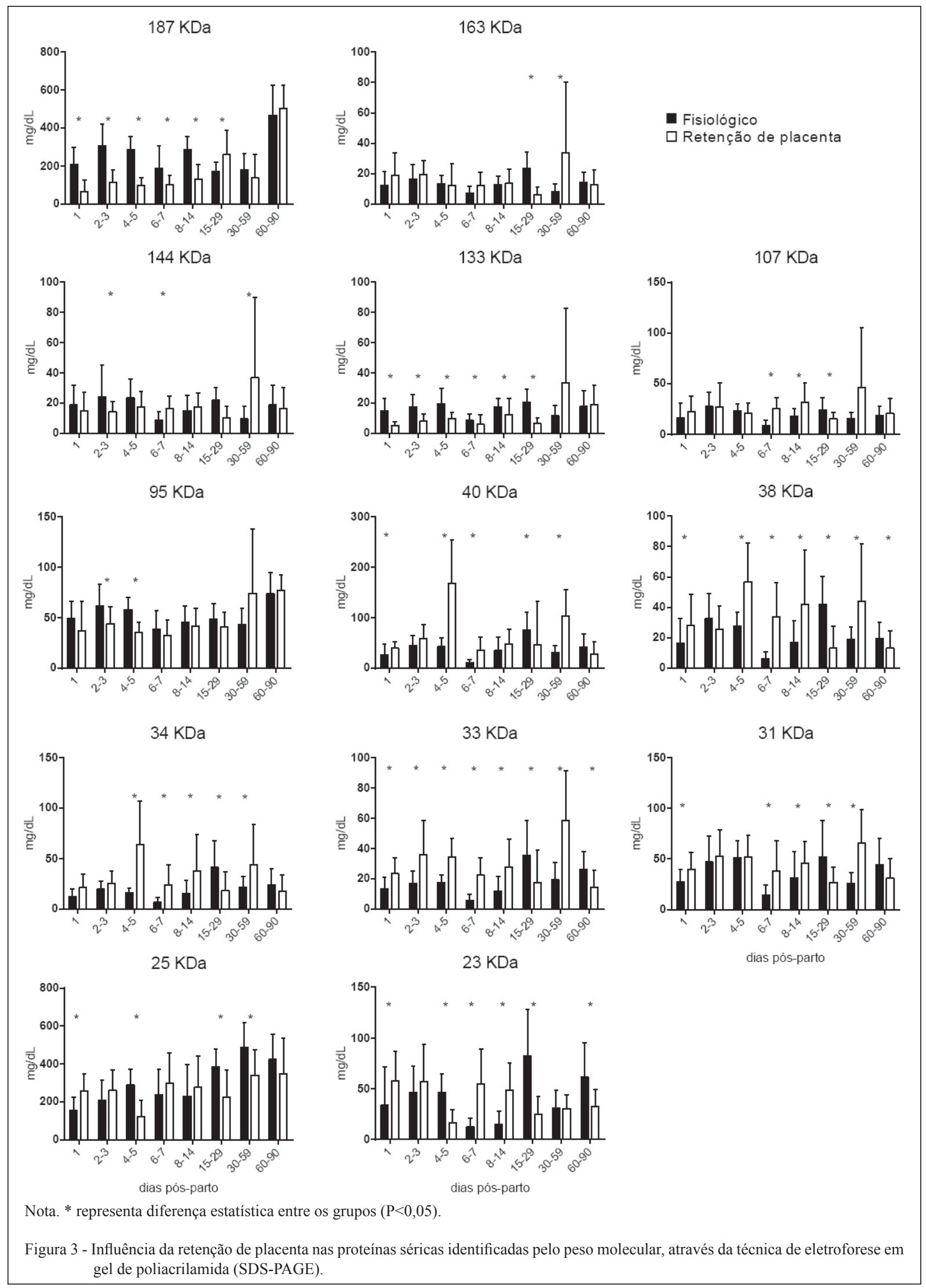

Ciência Rural, v.44, n.9, set, 2014. 


\section{COMITÊ DE ÉTICA E BIOSSEGURANÇA}

O presente trabalho foi aprovado pela Comissão de Bioética - FMVZ - USP (Protocolo no993/2006).

\section{REFERENCIAS}

BIRGEL, E.H.Leucoseenzoótica dos bovinos adultos: aspectos clínicos e diagnósticos. In: BIRGEL, E.H.; BENESI, F.J. Patologia clínica veterinária. 2.ed. São Paulo: Sociedade Paulista de Medicina Veterinária, 1982. p.249-260.

BONNEVILLE-HÉBERT, A. et al. Effect of reproductive disorders and parity on repeat breeder status and culling of dairy cows in Quebec. Canadian Journal of Veterinary Research, v.75, n.2, p.147, 2011. Disponível em: <http://www.ncbi.nlm.nih.gov/pmc/ articles/PMC3062926/>. Acesso em: 27 maio, 2013

CHAN, J.P.W. et al.Association of increased serum acutephase protein concentrations with reproductive performance in dairy cows with postpartum metritis.Veterinary Clinical Pathology, v.39, n.1, p.72-78, 2010.Disponível em: <http://onlinelibrary. wiley.com/doi/10.1111/j.1939-165X.2009.00182.x/full>. Acesso em: 27 maio, 2013.doi: 10.1111/j.1939-165X.2009.00182.x.

CHAPINAL, $\mathrm{N}$. et al.The association of serum metabolites with clinical disease during the transition period. Journal of Dairy Science, v.94, n.10, p.4897-4903, 2011. Disponível em: <http:// dx.doi.org/10.3168/jds.2010-4075>. Acesso em: 27 maio, 2013. doi: $10.3168 /$ jds.2010-4075.

CURTIS, C.R. et al. Path analysis of dry period nutrition, postpartum metabolic and reproductive disorders, and mastitis in Holstein cows. Journal of Dairy Science, v.68, n.9, p.23472360, 1985. Disponível em: <http://dx.doi.org/10.3168/jds.S00220302(85)81109-7>. Acesso em: 27 maio, 2013. doi: 10.3168/jds. S0022-0302(85)81109-7.

FAGLIARI, J.J.; SILVA, S.L.Hemograma e proteinograma plasmático de eqüinos hígidos e de eqüinos acometidos por abdômem agudo, antes e após laparotomia. Arquivo Brasileiro de Medicina Veterinária e Zootecnia, v.54, n.6, p.559-567, 2002. Disponível em: <http://www.scielo.br/scielo.php?script=sci arttext\&pid=S0102-09352002000600001\&lng=pt\&nrm=iso\&tlng $=\mathrm{pt}>$. Acesso em: 27 maio, 2013 .

FERNANDES, C.A.C. et al. Impacto da retenção de placenta sobre a performance reprodutiva de vacas leiteiras.Revista Brasileira de Reprodução Animal, v.25, p.26-30, 2001.

GONCALVES, D.; KOZICKI, L.E. Perfis bioquímicos e imunológicos no período peripartal de vacas leiteiras com e sem retenção de placenta. Brazilian Journal of Veterinary Research and Animal Science, v.34, n.6, p.364-370, 1997.

HIRVONEN, J. et al. Acute-phase response in dairy cows with acute postpartum metritis. Theriogenology, v.51, n.6, p.10711083, 1999. Disponível em: <http://www.theriojournal.com/ article/S0093-691X\%2899\%2980012-0/abstract>. Acesso em: 27 maio, 2013.

HORADAGODA, N.U. et al. Acute phase proteins in cattle: discrimination between acute and chronic inflammation. Veterinary Record, v.144, n.16, p.437-441, 1999. Disponível em $<$ http://veterinaryrecord.bmj.com/content/144/16/437.abstract $>$. Acesso em: 27 maio, 2013.
HOSSEIN-ZADEH, N.G.; ARDALAN, M.Cow-specific risk factors for retained placenta, metritis and clinical mastitis in Holstein cows. Veterinary Research Communications, v.35, n.6, p.345354, 2011. Disponível em: <http://link.springer.com/article/10.1007/ s11259-011-9479-5\#page-1>. Acesso em: 27 maio, 2013.

HUZZEY, J.M. et al. Short communication: Haptoglobin as an early indicator of metritis. Journal of dairy science, v.92, n.2, p.621-625, 2009.Disponível em: <http://dx.doi.org/10.3168/jds.2008-1526>. Acesso em: 27 maio, 2013.doi: 10.3168/jds.2008-1526.

JAIN, N.C. Acute phase protein.In: KIRK, R.W. Curren veterinary therapy: small animal practice. Philadelphia: Saunders, 1989.p.468-471.

KANEKO, J.J. et al. Clinical biochemistry of domestic animals. 6.ed. San Diego: Academic, 2008. 916p

KATOH, N. Relevance of apolipoproteins in the development of fatty liver and fatty liver-related peripartum diseases in dairy cows. Journal of Veterinary Medical Science, v.64, n.4, p.293-307, 2002.Disponível em: <http://cat.inist.fr/?aModele=afficheN\&cpsi $\mathrm{dt}=13680625>$. Acesso em: 27 maio, 2013.

LEBLANC, S.J. et al. Defining and diagnosing postpartum clinical endometritis and its impact on reproductive performance in dairy cows. Journal of Dairy Science, v.85, n.9, p.2223-2236, 2002.Disponível em: <http://dx.doi.org/10.3168/jds.S0022-0302(02)74302-6>. Acesso em: 27 maio, 2013.doi: 10.3168/jds.S0022-0302(02)74302-6.

LONA, D.V.; ROMERO, R.C.Low levels of colostral immunoglobulins in some dairy cows with placental retention. Journal of Dairy Science, n.84, p.389-391, 2001. Disponível em: <http:/www.journalofdairyscience.org/ article/S0022-0302\%2801\%2974488-8/abstract>. Acesso em: 27 maio, 2013.doi: 10.3168/jds.S0022-0302(01)74488-8.

MULEI, C.M. et al. Retained foetal membranes in cattle: relationship between bacterial isolates, blood picture and systemic involvement. Indian Journal of Animal Sciences, v.63, p.235-235, 1993.

PASSOS, C.B. Infecção experimental em ovinos com Trypanosoma evansi (Steel, 1885) (Sarcomastigophora: Trypanomatidae). 2004. 236f. Tese (Doutorado em Clínica Médica Veterinária) - Faculdade de Ciências Agrárias e Veterinárias, Universidade Estadual Paulista, Jaboticabal, SP.

SKINNER, J.G. et al. Bovine haptoglobin response in clinically defined field conditions.VeterinaryRecord, v.128, n.7, p.147149, 1991. Disponível em: <http://veterinaryrecord.bmj.com/ content/128/7/147.abstract>. Acesso em: 27 maio, 2013.

SOUZA, R.M. et al. Influência do puerpério e da fase pós-puerperal na função hepática de vacas da raça holandesa criadas no estado de São Paulo. Ciência Animal Brasileira, v.9, n.1, p.141-147, 2008. Disponível em: $<$ https://www.revistas.ufg.br/index.php/vet/article/ view/844>. Acesso em: 27 maio, 2013.

SOUZA, R.M. et al. Inter-relações entre a função hepática, lipidograma e os distúrbios inflamatórios do endométrio (endometrites puerperais agudas, retenção dos anexos fetais e catarros genitais) de fêmeas bovinas da raça Holandesa. Ciência Animal Brasileira, v.11, n.4, p.880-887, 2010. Disponível em: < http://www.revistas.ufg.br/index.php/vet/article/ viewArticle/5123>. Acesso em: 27 maio, 2013.

WILLIAMS, E.J. et al. The relationship between uterine pathogen growth density and ovarian function in the postpartum dairy cow. Theriogenology, v.68, n.4,p.549-559,2007. Disponívelem: $<$ http:// www.ncbi.nlm.nih.gov/pmc/articles/PMC2702080/>. Acesso em: 27 maio, 2013.doi: 10.1016/j.theriogenology.2007.04.056. 